\title{
Association of delay of urgent or emergency surgery with mortality and use of health care resources: a propensity score-matched observational cohort study
}

\author{
Daniel I. Mclsaac MD MPH, Karim Abdulla MD, Homer Yang MD, Sudhir Sundaresan MD, Paula Doering RN, \\ Sandeep Green Vaswani MBA, Kednapa Thavorn MPharm PhD, Alan J. Forster MD MSc
}

— Cite as: CMAJ 2017 July 10;189:E905-12. doi: 10.1503/cmaj.160576

See related article at www.cmaj.ca/lookup/doi/10.1503/cmaj.170172

\begin{abstract}
BACKGROUND: Delay of surgery for hip fracture is associated with increased risk of morbidity and mortality, but the effects of surgical delays on mortality and resource use in the context of other emergency surgeries is poorly described. Our objective was to measure the independent association between delay of emergency surgery and in-hospital mortality, length of stay and costs.
\end{abstract}

METHODS: We identified all adult patients who underwent emergency noncardiac surgery between January 2012 and October 2014 at a single tertiary care centre. Delay of surgery was defined as the time from surgical book- ing to operating room entry exceeding institutionally defined acceptable wait times, based on a standardized 5-level priority system that accounted for surgery type and indication. Patients with delayed surgery were matched to those without delay using propensity scores derived from variables that accounted for details of admission and the hospital stay, patient characteristics, physiologic instability, and surgical urgency and risk.

RESULTS: Of 15160 patients, 2820 $(18.6 \%)$ experienced a delay. The mortality rates were $4.9 \%(138 / 2820)$ for those with delay and 3.2\% (391/12 340) for those without delay (odds ratio [OR]
1.59, 95\% confidence interval $[\mathrm{Cl}] 1.30$ 1.93). Within the propensity-matched cohort, delay was significantly associated with mortality (OR $1.56,95 \% \mathrm{Cl}$ 1.18-2.06), increased length of stay (incident rate ratio $1.07,95 \% \mathrm{Cl} 1.01-$ 1.11) and higher total costs (incident rate ratio $1.06,95 \% \mathrm{Cl} 1.01-1.11$ ).

INTERPRETATION: Delayed operating room access for emergency surgery was associated with increased risk of inhospital mortality, longer length of stay and higher costs. System issues appeared to underlie most delays and must be addressed to improve the outcomes of emergency surgery.

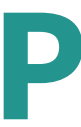

atients undergoing emergency surgery are at high risk of adverse outcomes. ${ }^{1}$ Although patient characteristics ${ }^{2,3}$ and surgical indication $\mathrm{n}^{4,5}$ are the most important risk factors, system factors, such as delayed access to the operating room, also affect outcomes. In hip fracture surgery, delay is associated with morbidity and mortality, ${ }^{6,7}$ but for other surgeries, the effect of delay on outcomes is unclear. ${ }^{8-13}$ Because it is very expensive to expand or reorganize operating room resources to improve access, ${ }^{14-16}$ understanding the relation between delay and outcomes for all types of emergency surgery is needed.
The association between surgical delay and outcome may be obscured by confounding. The indication for surgery, comorbidities and physiologic disturbances may influence both the risk of delay and the risk of adverse outcomes. Furthermore, ascertainment of delay is a challenge. Many studies measure surgical wait time as the time from admission to surgery, but this is misleading, because inpatient work-up is often required to determine the risks and potential benefits of surgery.

The purpose of this study was to determine the independent association of surgical delay with inpatient mortality, postoperative length of stay and total costs of hospital care. 


\section{Methods}

\section{Design and setting}

We performed a retrospective cohort study of emergency inpatient surgery at The Ottawa Hospital, a 900-bed academic health sciences centre serving a population of 1.2 million people. With 2 distinct campuses that perform emergency surgery, our institution is the regional cancer centre and the sole regional provider for trauma surgery, neurosurgery, thoracic surgery and vascular surgery. On weekdays, 5 or 6 of our 35 operating rooms are dedicated to emergency surgery; 3 of these rooms are available until $11 \mathrm{pm}$, and 2 are available between $11 \mathrm{pm}$ to $7 \mathrm{am}$. All surgeons and anesthesiologists are paid on a fee-for-service basis.

Using established methods, ${ }^{17}$ our hospital developed and adopted new wait time standards for emergency operating room access in January 2012 (described in detail in Appendix 1, available at www.cmaj.ca/lookup/suppl/doi:10.1503/cmaj.160576/-/DC1). All emergency cases were classified into 1 of 5 urgency categories ( $\mathrm{A},<45 \mathrm{~min} ; \mathrm{B},<2 \mathrm{~h} ; \mathrm{C},<4 \mathrm{~h} ; \mathrm{D},<8 \mathrm{~h} ; \mathrm{E},<24 \mathrm{~h}$ ), according to the surgical procedure and patient indication. ${ }^{18}$ The booking process was also clarified: patients could not be booked unless they were appropriately prepared to come to the operating room at any time after booking. The urgency classification was applied by the surgeon and was documented in the Surgical Information Management System. If there was a change in patient status (such as acute deterioration), the urgency classification could be changed accordingly.

\section{Data sources}

All data used in this study were derived from the data warehouse of The Ottawa Hospital, which stores clinical and administrative data. We used the Canadian Institute for Health Information Discharge Abstract Database; the National Ambulatory Care Reporting System; the Surgical Information Management System, which records all details of surgical procedures performed in our hospital operating rooms; and the electronic health record database at The Ottawa Hospital. Data sources are described in Appendix 2 (available at www.cmaj.ca/lookup/suppl/doi:10.1503/cmaj.160576/-/DC1).

\section{Study population}

We identified all adults undergoing emergency noncardiac surgery from January 2012 to October 2014. The study start date represents the implementation date of our 5-level prioritization system, and October 2014 was the last date at which all data sets were complete. We included all patients who were scheduled for emergency surgery and who entered the operating room within 3 multiples of the wait time for their assigned priority (representing the 95th percentile of wait times); we excluded patients who waited beyond this time frame because they may have been substantively different from those who waited less than 3 multiples of the accepted wait time (by virtue of their ability to survive this extended wait). All cases at The Ottawa Hospital are booked in the Surgical Information Management System as elective or emergent. Emergent cases are defined as those in which a patient is booked for surgery following evaluation and admission to hospital; elective cases are planned before admission. For our analysis, we included only cases in which the patient's clinical presentation necessitated operating room access within 24 hours.

\section{Exposure}

The exposure was surgical delay, defined as a wait time from surgical booking to the patient entering the operating room in excess of the accepted wait time for the patient's priority level. At the time of booking, each patient was assigned a priority level on the basis of our wait time standards (Appendix 3, available at www.cmaj. ca/lookup/suppl/doi:10.1503/cmaj.160576/-/DC1). For our primary analysis, the exposure was treated as binary (delayed v. nondelayed). We classified each patient's urgency status according to the status in effect at the time of entry into the operating room.

When the acceptable wait time was exceeded, the operating room manager could submit 1 of 8 prepopulated reasons into the Surgical Information Management System to capture the reason for delay.

\section{Outcomes}

Our primary outcome was in-hospital mortality, the accuracy of which has been validated. ${ }^{19}$ Length of stay was defined as the number of days from surgery to hospital discharge. Total hospital costs, calculated on a hospital-specific basis using standardized methods, included both direct and indirect costs standardized to 2014 Canadian dollars. ${ }^{20}$ This method accounts for an individual patient's resource intensity weight and case-mix group, as well as fixed and indirect costs to the hospital based on the patient's location of care and length of stay.

\section{Covariables}

We specified covariables a priori on the basis of their likely role as confounders, through a structured literature review guided by an information specialist, the surgical risk calculator of the National Surgical Quality Improvement Program (American College of Surgeons) ${ }^{3}$ and existing systematic reviews. ${ }^{2}$ The full list of covariables and their representation in our models are available in Appendix 4 (available at www.cmaj.ca/lookup/suppl/ doi:10.1503/cmaj.160576/-/DC1). We used several risk indices: Procedural Index for Mortality Risk, an internally validated index that predicts the risk of in-hospital death according to surgical procedure; ${ }^{5}$ the Elixhauser Index, ${ }^{21}$ an internally validated score that assigns points to comorbidities to predict in-hospital mortality; ${ }^{22}$ and the Laboratory-Based Acute Physiology Score, an externally validated score that predicts physiology-associated mortality risk on the basis of laboratory values. ${ }^{23}$

\section{Missing data}

No outcome or exposure data were missing. Not all laboratory tests were ordered for all patients; we used published methods to impute missing values for the laboratory tests used in the Laboratory-Based Acute Physiology Score. ${ }^{23}$

\section{Statistical analysis}

We compared patient characteristics between groups using standardized differences, with differences of less than $10 \%$ being thought to represent negligible correlations. ${ }^{24}$ 
The primary analysis consisted of unadjusted and propensity score-matched analyses to measure the association between surgical delay and death. We used a nonparsimonious multivariable logistic regression model to estimate the propensity for delay for each patient. We included all variables postulated to act as confounders between delay and outcome (Appendix 4). We matched patients $1: 1$ without replacement based on a caliper ( 0.2 standard deviations of the propensity score logit) in a greedy matching algorithm (\% gmatch). ${ }^{25}$ Match quality was assessed in terms of the covariable balance between exposure groups and the achievement of a high proportion of matched exposed patients. ${ }^{26}$ We measured the association between delay and mortality using a $\chi^{2}$ test; the absolute risk difference and number needed to harm were also calculated. We tested an interaction between priority level and delay status to evaluate whether the effect of delay on mortality differed across priority levels.

For secondary analyses of length of stay and cost, we used the same matched cohort. Because the length of stay and cost distributions were skewed, we used nonparametric Wilcoxon signedrank tests. We calculated relative associations using generalized linear models with log-link and gamma (cost) or negative binomial (length of stay) distributed errors.

We conducted several prespecified sensitivity analyses. We used the propensity score to assign inverse probability of treatment weights. This allowed us to calculate the average treatment effect, as opposed to the average treatment effect for the treated patients from the matched analysis. ${ }^{27}$ We used prespecified inverse probability of treatment weight analyses based on subgroup-specific propensity scores to evaluate the robustness of our primary analysis with exclusion of hip fractures and exclusion of individuals delayed for medical reasons. We also performed a post hoc analysis restricted to patients with hip fracture.
Finally, we analyzed a continuous, but possibly nonlinear, relation between wait time and mortality, in contrast to the binary exposure used in our primary analysis. Wait times were standardized among priority levels by dividing the wait time in minutes by the accepted wait-time window. We used a generalized additive model, adjusting for procedural mortality risk (with the Procedural Index for Mortality Risk score) and patient comorbidity (with the Elixhauser Index) to analyze the continuous association between wait time and mortality. Splines with 3 degrees of freedom were used for each variable.

We used SAS version 9.4 (SAS Institute Inc.) for data management and analysis.

\section{Ethics approval}

This study was approved by the Ottawa Health Science Network Research Ethics Board.

\section{Results}

A total of 15275 emergency surgery patients were identified (Figure 1). We excluded 115 patients because their wait times exceeded 3 multiples of the accepted wait-time window. Of the 15160 included patients, 12340 (81.4\%) reached the operating room within an acceptable wait time, whereas 2820 (18.6\%) did not (Table 1). The reasons for delay were documented in 1109 cases (39.3\% of all delays; Table 2). Risk of mortality did not differ between patients with and without a documented reason for delay, and mean excess wait times are described in Appendix 5 (available at www.cmaj.ca/lookup/suppl/doi:10.1503/cmaj.160576/-/DC1). In $958(86.4 \%)$ of the cases with a documented reason for delay, system issues such as availability of human or physical resources were identified as the reason for delay. The most common surgical procedures for each priority level are shown in Table 3.

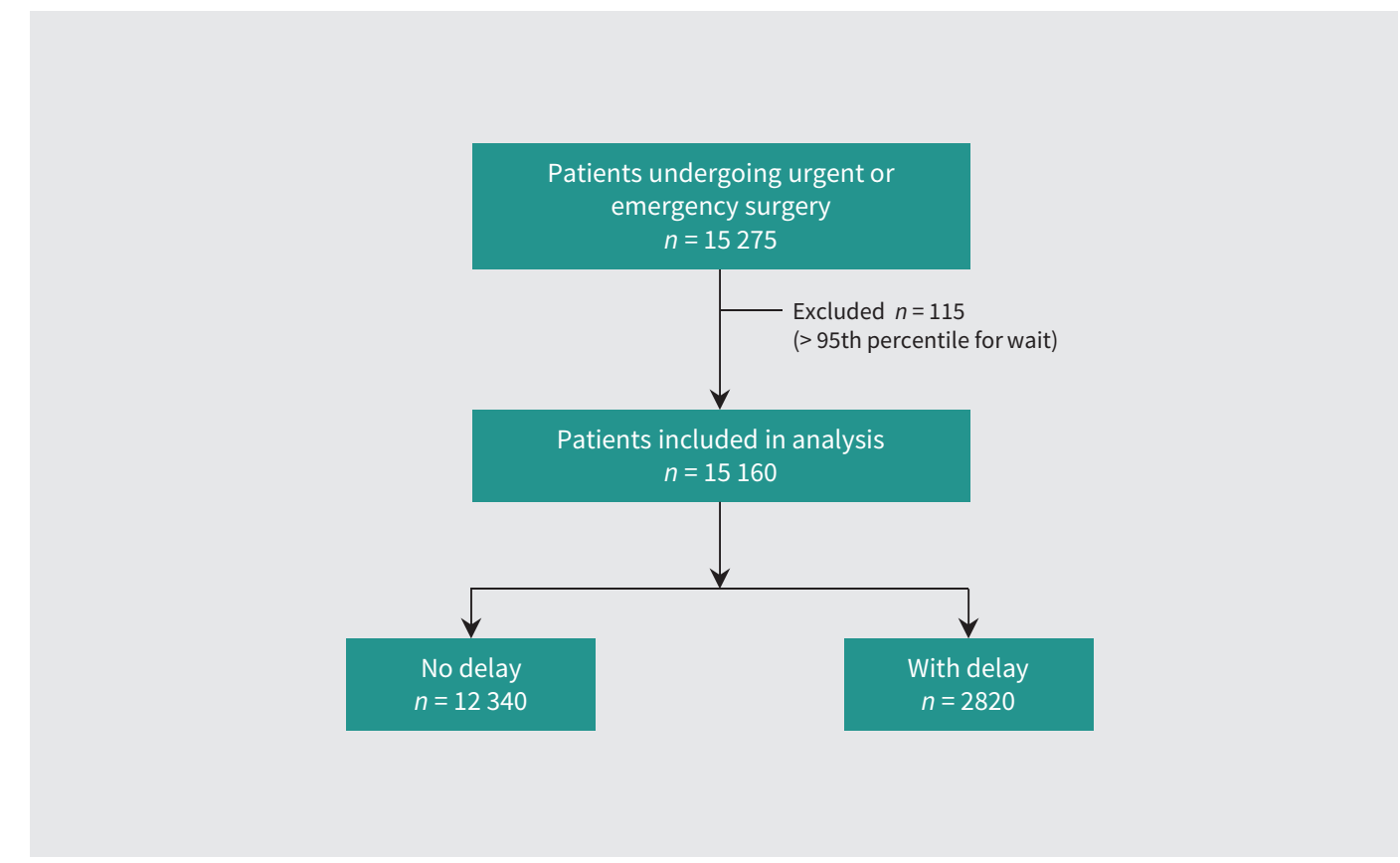

Figure 1: Study flow diagram. 
Table 1: Demographic characteristics

$\%$ of entire cohort*

$\%$ of propensity score-matched cohort ${ }^{\star}$

$\begin{array}{cccccc} & & \text { Absolute } & \text { Absolute } & \text { Delayed } & \text { standardized } \\ \text { Characteristic } & \text { Nondelayed } & \text { Delayed } & \begin{array}{c}\text { standardized } \\ \text { differencet }\end{array} & \begin{array}{c}\text { Nondelayed } \\ n=2820\end{array} & \begin{array}{c}\text { Delayed } \\ n=2820\end{array} \\ \text { difference }\end{array}$

Priority level

A

B

C

D

E

Age, yr, mean \pm SD

Sex, female

Elixhauser Index, mean (IQR)

Hospital admission status, urgent

Hospital entry through ED

ASA physical status score

I and II

III and IV

V

Surgical service of record

Dental

General surgery

Gynecology

Neurosurgery

Ophthalmology

Orthopedic surgery

Otolaryngology

Plastic surgery

Thoracic surgery

Urology

Vascular surgery

Other

Direct to operating theatre from ED

In ICU when surgery booked

PIMR score, mean $\pm S D$

CTAS$$
1
$$$$
\text { 4-5 }
$$

Transfusion within $24 \mathrm{~h}$ before surgery

Piperacillin-tazobactam or meropenem

before arrival in operating room

Preoperative steroids

Preoperative insulin

LAPS, mean \pm SD

$$
2
$$

\begin{tabular}{c}
4.6 \\
7.5 \\
10.2 \\
\hline 29.9 \\
\hline 47.9
\end{tabular}

$56.7 \pm 20.7$

50.0

$2.0(4.4)$

95.2

84.8

32.0

65.7

2.2

1.0

32.3

5.0

7.2

1.5

27.3

2.0

1.6

2.2

12.0

7.2

0.8

9.3

3.2

$0.7 \pm 1.5$

\section{6}

40.8

52.8

2.9

3.7

6.6

4.0

11.5

$22.6 \pm 24.1$

7.4
5.4
7.1
12.2
67.9

$60.8 \pm 20.3$

51.9

$2.0(4.4)$

95.6

84.7

25.8

71.8

2.3

1.9

21.1

2.6

8.2

1.2

42.2

1.9

0.8

2.6

9.5

7.6

0.1

3.5

3.5

$0.9 \pm 1.5$

2.7

37.4

57.8

2.2

5.5

8.2

5.6

14.9

$22.0 \pm 37.2$
11.8

8.6

16.7

44.5

41.4

14.7

3.8

0

1.9

0.3

13.7

13.2

0.7

7.5

25.5

12.6

3.8

2.6

31.7

0.7

7.4

2.6

37.5

1.5

3.7

23.9

1.7

10.0

5.2

7.0

10.1

4.4

8.6

6.1

7.5

10.1

1.9
6.4

$$
5.4
$$

7.3

12.0

68.9

$59.5 \pm 20.8$

50.3

1.9 (4.3)

95.7

84.6

28.3

69.7

1.9

$$
2.0
$$

21.1

2.4

8.6

1.3

41.9

1.8

$$
0.8
$$

$$
2.6
$$

$$
9.9
$$

$$
7.1
$$$$
0.1
$$

3.2

$0.9 \pm 1.6$

\section{0}

37.5

56.4

2.9

4.3

7.4

5.2
13

$22.4 \pm 21.7$
3.9

0

0.8

0.6

2.2

6.3

3.2

4.6

0.5

0.3

5.6

4.6

2.8

2.3

0.7

0

1.3

1.4

0.9

0.6

0.7

0

0

1.4

1.9

0

1.7

1.7

0

Note: ASA = American Society of Anesthesiology physical status score (higher categories predict higher risk of death), CTAS = Canadian Emergency Department Triage and Acuity Scale, $\mathrm{ED}=$ emergency department, ICU = intensive care unit, IQR = interquartile range, LAPS = Laboratory Acute Physiology Score (range 0-256; higher scores predict higher risk of death), PIMR = Procedural Index for Mortality Risk, SD = standard deviation.

${ }^{\star}$ Except where indicated otherwise.

†Absolute standardized differences $>10$ are considered represent an important difference. 
Crude mortality rate, length of stay and costs were higher in the group whose surgery was delayed (Table 4). We matched each of the 2820 delayed patients with a nondelayed patient using propensity scores, and achieved a balance of covariables (Table 1; Appendix 6, available at www.cmaj.ca/lookup/suppl/ doi:10.1503/cmaj.160576/-/DC1). Within the matched cohort, the risk of in-hospital mortality, length of stay and costs were all significantly higher in the delayed group (Table 4). The number needed to harm for mortality was 60 ; the odds ratio (OR) was 1.56 (95\% confidence interval $[\mathrm{Cl}] 1.18-2.06)$. An interaction term between priority level and delay status was not statistically significant $(p=0.4)$.

\section{Sensitivity analyses}

Inverse probability of treatment weight groups were balanced across covariables (Appendix 7, available at www.cmaj.ca/ lookup/suppl/doi:10.1503/cmaj.160576/-/DC1). In the full cohort, patients with delay were more likely to die (OR 1.35, 95\% Cl 1.081.69). When hip fractures were excluded, patients with delay had a $28 \%$ increase in relative odds of mortality (OR 1.28, 95\% Cl 1.001.65). When patient-specific delays were excluded, delay was associated with mortality (OR 1.51, 95\% Cl 1.14-2.00). Delay was also associated with mortality in the post hoc analysis of patients with hip fracture (OR 1.64, 95\% Cl 1.05-2.61). Appendix 8 (available at www.cmaj.ca/lookup/suppl/doi:10.1503/cmaj.160576/-/ DC1) contains other post hoc analyses.

When we modelled the odds of mortality as a nonlinear continuous association with wait time, we found a significant, biphasic association $(p=0.01)$. The shape of the spline suggested that as the wait increased up to 1.1 multiples of the accepted wait-time window, the odds of mortality increased; beyond 1.1 multiples of the accepted wait-time window, the odds of mortality decreased. At 0.4 multiples of the accepted wait-time window, the odds of death crossed the null value (odds $=1$ ), suggesting that beyond this point, excess mortality was attributable to increasing wait time (up to the 1.1 multiples of the accepted wait-time window inflection point; Figure 2).

\section{Interpretation}

Delay of operating room access for emergency surgery was independently associated with an increased risk of in-hospital mortality, longer length of stay and higher total hospital costs. Importantly, system factors, such as the availability of clinicians and physical resources, appeared to be the main reasons for delay of emergency surgery. We used validated indices to adjust for physiologic disturbance, preoperative therapies and timing of the decision to operate; this approach allowed us to address the limitations of prior research, which was unable to account for many acute preoperative patient variables and relied upon the time from hospital admission to operating room entry, ${ }^{7}$ and to gain new insights into the implications of delay of surgery on use of health care resources.

Improving operating room access for patients needing emergency surgery will require careful consideration of the

\begin{tabular}{|l|l|}
\hline Table 2: Reasons for delay in access $(\boldsymbol{n}=\mathbf{1 1 0 9})$ & $\begin{array}{c}\text { No. }(\%) \text { of } \\
\text { patients }\end{array}$ \\
\hline Reason & $352(31.7)$ \\
\hline Availability of personnel & 42 \\
\hline Anesthesiologist & 5 \\
\hline Nurse & 305 \\
\hline Surgeon & $147(13.3)$ \\
\hline Availability of physical resources & 122 \\
\hline Operating room & 11 \\
\hline Postanesthesia care unit & 14 \\
\hline Equipment & $459(41.4)$ \\
\hline Multifactorial delay & 459 \\
\hline Bumped by higher priority case & $151(13.6)$ \\
\hline Patient-specific delay & 151 \\
\hline Medically complex or decompensated patient &
\end{tabular}

Table 3: Most common surgical procedures for each priority level

Priority level; reason and \% of cases (by priority level)

\section{Priority A \\ $n=770$}

Ruptured abdominal aortic aneurysm (9.6\%)

Peripheral arterial bypass for acute distal ischemia (8.0\%)

Craniotomy for acute intracranial condition (7.6\%)

\section{Priority B
$n=1082$}

Small-bowel repair or bypass for acute peritonitis (11.1\%)

Large-bowel repair or bypass for acute peritonitis (10.2\%)

Peripheral arterial bypass for vein graft occlusion (5.2\%)
Priority C
$n=1456$

Hernia repair with bowel obstruction (9.0\%)

Small-bowel repair or bypass for bowel obstruction (6.8\%)

Large-bowel repair or bypass for bowel obstruction (5.4\%)
Priority D

$n=4028$

Laparoscopic appendectomy (28.1\%)

Laparoscopic cholecystectomy (4.8\%)

Hernia repair (no peritonitis or bowel obstruction) (4.7\%)
Abdominal wall repair

(8.2\%)

\section{Priority E} $n=7824$

ORIF hip or neck of femur $(27.5 \%)$

Ureteroscopy (5.6\%)

Note: ORIF = open reduction internal fixation . 
perioperative health care system, in particular how to optimize utilization of currently available resources and how to balance the increased resources that may be needed to improve access with the expected benefit of improved outcomes. We found that many delays were due to physician unavailability. Therefore, improving availability of personnel may improve access without increasing costs (at least from a hospital perspective). Furthermore, the increased resources required to have ade- quate nursing personnel and physical resources should be partially offset by decreased hospital costs independently attributed to surgical delay.

Considering the mechanisms underlying the delay-mortality relation, which in hip surgery may be attributable to hospitalacquired complications, might also help to properly target resources. ${ }^{7}$ Unfortunately, our data do not contain validated measures of complications to support the generalizability of this mech-

\begin{tabular}{|c|c|c|c|c|}
\hline Outcome & Nondelayed & Delayed & $\begin{array}{l}\text { Absolute } \\
\text { difference }\end{array}$ & $\begin{array}{l}\text { Relative association* } \\
\qquad(95 \% \mathrm{Cl})\end{array}$ \\
\hline Unadjusted & $n=12340$ & $n=2820$ & & \\
\hline In-hospital death, no. (\%) & $391(3.2)$ & $138(4.9)$ & 1.6 & $1.59(1.30-1.93)$ \\
\hline Length of stay, $d$, mean \pm SD & $11 \pm 19.1$ & $13.6 \pm 20.4$ & 2.6 & $1.21(1.16-1.25)$ \\
\hline $\begin{array}{l}\text { Total hospital costs, } \uparrow \$ \text {, } \\
\text { mean } \pm \text { SD }\end{array}$ & $19144 \pm 33900$ & $22479 \pm 40224$ & 3335 & $1.17(1.13-1.21)$ \\
\hline $\begin{array}{l}\text { Propensity score match } \\
\text { adjusted }\end{array}$ & $n=\mathbf{2 8 2 0}$ & $n=2820$ & & \\
\hline In-hospital death, no. (\%) & $90(3.2)$ & $138(4.9)$ & 1.7 & $1.56(1.18-2.06)$ \\
\hline Length of stay, $d$, mean \pm SD & $12.5 \pm 20.7$ & $13.6 \pm 20.4$ & 1.1 & $1.07(1.01-1.11)$ \\
\hline $\begin{array}{l}\text { Total hospital costs, } \uparrow \$ \text {, } \\
\text { mean } \pm \text { SD }\end{array}$ & $20989 \pm 35085$ & $22479 \pm 40224$ & 1490 & $1.06(1.01-1.11)$ \\
\hline
\end{tabular}

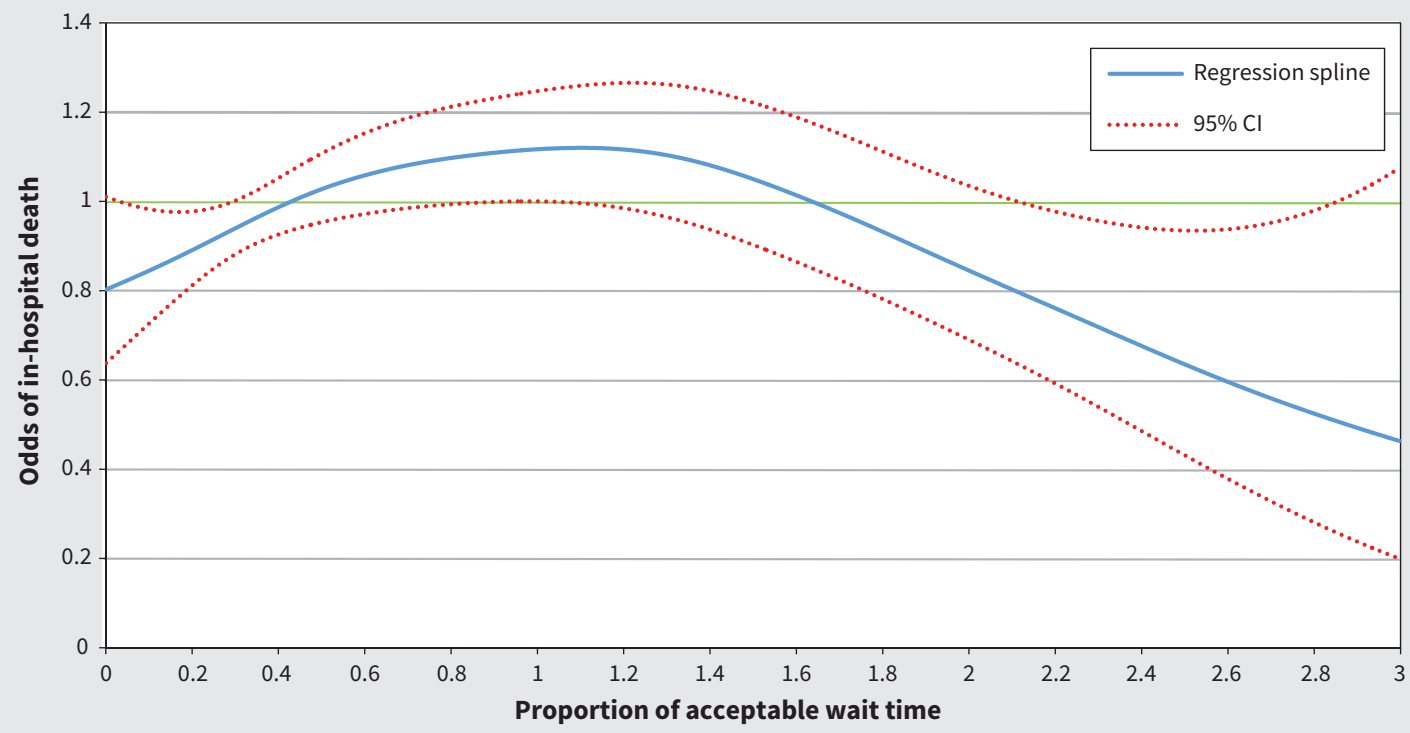

Figure 2: Spline of risk of in-hospital death as a function of wait time. The adjusted regression spline presents the proportion of acceptable wait time experienced by emergency surgical patients as a function of the odds of in-hospital death. Where the spline and $95 \%$ confidence limits are greater than the green line at 1 , there is a significantly increased risk of death. $\mathrm{Cl}=$ confidence interval. 
anism. However, we did find a nonlinear association between wait time and mortality, which suggests opportunities to match patient need for rapid operating room access with scarce resources. The odds of dying increased for waits of up to 1.1 multiples of the accepted wait-time window, and decreased thereafter. This relation suggests that there may be 2 subgroups of patients. One group truly appears to need urgent surgical intervention; in these patients, longer waits may increase the risk of death. Decreasing mortality risk beyond 1.1 wait-time multiples may indicate a group experiencing survivorship bias, whose outcome is not as sensitive to longer wait times for surgery. Therefore, a more granular approach, considering both patient and procedural characteristics, is needed to appropriately map wait-time standards to tolerance for waiting. Because the odds of death crossed the null value (odds $=1$ ) at 0.4 wait-time multiples, the wait times established by our hospital may be too long. Prospective research that provides a clear understanding of the interaction between patient and procedural risk is needed to inform stakeholders in the application of scarce health care resources aimed at improving emergency surgery outcomes through more timely operating room access. Our findings that many emergency surgical cases are delayed, that delays are typically due to system issues and that delays are associated with adverse outcomes are consistent with the existing literature. In the current study, about $20 \%$ of patients needing emergency surgery did not gain access to the operating room in a time frame compliant with our institutional guidelines, and $86.4 \%$ of delays were attributable to system factors, similar to the findings of previous studies. ${ }^{28-30}$ In the United Kingdom, only $1 \%$ of emergency surgeries may be delayed because patient resuscitation is needed, and the majority of cases with delay experience organizational problems. ${ }^{29}$ Among emergency laparotomies, 77\% of delays were related to being bumped by higher-priority cases or unavailability of operating rooms. ${ }^{28}$

Although our results support the known association between delay and mortality in patients with hip fracture, ${ }^{7}$ they also support the generalizability of the delay-outcome association to nonorthopedic surgery, where previous findings have both supported $^{8,9}$ and refuted ${ }^{10,11}$ this association. There are about 100000 emergency general surgery operations, ${ }^{31}$ and 30000 hip fracture operations annually in Canada. ${ }^{32}$ If $20 \%$ of these cases experience delays, we estimate that more than 410 deaths may be attributable to surgical delay each year. A randomized trial of timing of hip fracture surgery is ongoing, ${ }^{33}$ but randomized data are also needed to evaluate the effect of timing of emergency surgery for other indications.

\section{Limitations}

A causal and generalizable relation between delay of surgery and death cannot be determined from a single-centre observational study; a randomized trial would be required. Despite our use of robust methods, confounding and unmeasured covariables are threats to the validity of our results. Our primary classification of delay was dichotomization of a continuous variable; our sensitivity analysis based on a generalized additive model was a secondary analysis, and must be interpreted as such. Our classification of delay was based on a prioritization system that has not been tested with regard to its effect on outcomes. The reported reasons for noncompliance with timing of emergency surgery were missing for about $60 \%$ of patients. Finally, we cannot account for deaths that may have occurred outside our institution.

\section{Conclusion}

Delay in operating room access for emergency surgery is associated with increases in mortality risk, length of stay and costs. These findings are consistent with increasing evidence showing that delays in emergency surgery cause harm. Improving timely access to emergency surgery may require reallocation of scarce resources; however, such reallocation may be offset by savings derived from avoiding delays.

\section{References}

1. Haider AH, Obirieze A, Velopulos CG, et al. Incremental cost of emergency versus elective surgery. Ann Surg 2015;262:260-6.

2. Davis P, Hayden J, Springer J, et al. Prognostic factors for morbidity and mortality in elderly patients undergoing acute gastrointestinal surgery: a systematic review. Can J Surg 2014;57:E44-52.

3. Bilimoria KY, Liu Y, Paruch JL, et al. Development and evaluation of the universal ACS NSQIP surgical risk calculator: a decision aid and informed consent tool for patients and surgeons. J Am Coll Surg 2013;217:833-42.e1-3.

4. Fleisher LA, Beckman JA, Brown KA, et al.; American College of Cardiology/ American Heart Association Task Force on Practice Guidelines (Writing Committee to Revise the 2002 Guidelines on Perioperative Cardiovascular Evaluation for Noncardiac Surgery); American Society of Echocardiography; American Society of Nuclear Cardiology; Heart Rhythm Society; Society of Cardiovascular Anesthesiologists; Society for Cardiovascular Angiography and Interventions; Society for Vascular Medicine and Biology; Society for Vascular Surgery. ACC/AHA 2007 guidelines on perioperative cardiovascular evaluation and care for noncardiac surgery: executive summary: a report of the American College of Cardiology/American Heart Association Task Force on Practice Guidelines (Writing Committee to Revise the 2002 Guidelines on Perioperative Cardiovascular Evaluation for Noncardiac Surgery). Anesth Analg 2008;106:685-712.

5. van Walraven C, Wong J, Bennett C, et al. The Procedural Index for Mortality Risk (PIMR): an index calculated using administrative data to quantify the independent influence of procedures on risk of hospital death. BMC Health Serv Res 2011;11:258.

6. Moja L, Piatti A, Pecoraro V, et al. Timing matters in hip fracture surgery: patients operated within 48 hours have better outcomes. A meta-analysis and meta-regression of over 190,000 patients. PLoS One 2012; 7:e46175.

7. Simunovic N, Devereaux PJ, Sprague S, et al. Effect of early surgery after hip fracture on mortality and complications: systematic review and meta-analysis. CMAJ 2010;182:1609-16.

8. Buck DL, Vester-Andersen M, Møller MH. Surgical delay is a critical determinant of survival in perforated peptic ulcer. Br J Surg 2013;100:1045-9.

9. Azuhata T, Kinoshita K, Kawano D, et al. Time from admission to initiation of surgery for source control is a critical determinant of survival in patients with gastrointestinal perforation with associated septic shock. Crit Care 2014;18:R87.

10. Vester-Andersen M, Lundstrøm LH, Buck DL, et al. Association between surgical delay and survival in high-risk emergency abdominal surgery. A population-based Danish cohort study. Scand J Gastroenterol 2016;51:121-8.

11. Sicard N, Tousignant $P$, Pineault R. Non-patient factors related to rates of ruptured appendicitis. Br J Surg 2007;94:214-21.

12. Ong M, Guang TY, Yang TK. Impact of surgical delay on outcomes in elderly patients undergoing emergency surgery: a single center experience. World $\mathrm{J}$ Gastrointest Surg 2015;7:208-13.

13. Ingraham AM, Cohen ME, Bilimoria KY, et al. Effect of delay to operation on outcomes in adults with acute appendicitis. Arch Surg 2010;145:886-92.

14. Anantha RV, Paskar D, Vogt K, et al. Allocating operating room resources to an acute care surgery service does not affect wait-times for elective cancer surgeries: a retrospective cohort study. World J Emerg Surg 2014;9:21.

15. Heng M, Wright JG. Dedicated operating room for emergency surgery improves access and efficiency. Can J Surg 2013;56:167-74.

16. Hameed SM, Brenneman FD, Ball CG, et al.; Canadian Association of General Surgery Committee on Acute Surgery and Critical Care. General surgery 2.0: the emergence of acute care surgery in Canada. Can J Surg 2010;53:79-83. 
17. Smith CD, Spackman T, Brommer K, et al. Re-engineering the operating room using variability methodology to improve health care value. J Am Coll Surg 2013;216:559-68.

18. Ryckman FC, Adler E, Anneken AM, et al. Cincinnati Children's Hospital Medical Center: redesigning perioperative flow using operations management tools to improve access and safety.. In: Litvak E, editor. Managing patient flow in hospitals: strategies and solutions. 2nd ed. Oak Brook (IL): Joint Commission Resources; 2009:97-111.

19. Juurlink D, Preyra C, Croxford R, et al. Canadian Institute for Health Information Discharge Abstract Database: a validation study [ICES investigative report]. Toronto: Institute for Clinical Evaluative Sciences; 2006.

20. Wodchis WP, Bushmeneva K, Nikitovic M, et al. Guidelines on person-level costing using administrative databases in Ontario. Working Paper Series Vol. 1. Toronto: University of Toronto, Institute of Health Policy, Management and Evaluation, Health System Performance Research Network; 2013. Available: www.hsprn.ca/uploads/files/Guidelines_on_PersonLevel_Costing_May_2013. pdf (accessed 2016 Sept. 19).

21. Quan H, Sundararajan V, Halfon P, et al. Coding algorithms for defining comorbidities in ICD-9-CM and ICD-10 administrative data. Med Care 2005;43:1130-9.

22. van Walraven $C$, Austin PC, Jennings A, et al. A modification of the Elixhauser comorbidity measures into a point system for hospital death using administrative data. Med Care 2009;47:626-33.

23. Escobar GJ, Greene JD, Scheirer P, et al. Risk-adjusting hospital inpatient mortality using automated inpatient, outpatient, and laboratory databases. Med Care 2008;46:232-9
24. Austin PC. Using the standardized difference to compare the prevalence of a binary variable between two groups in observational research. Commun Stat Simul Comput 2009;38:1228-34.

25. Austin PC. A critical appraisal of propensity-score matching in the medical literature between 1996 and 2003. Stat Med 2008;27:2037-49.

26. Ali MS, Groenwold RHH, Belitser SV, et al. Reporting of covariate selection and balance assessment in propensity score analysis is suboptimal: a systematic review. J Clin Epidemiol 2015;68:112-21.

27. Austin PC, Laupacis A. A tutorial on methods to estimating clinically and policy-meaningful measures of treatment effects in prospective observational studies: a review. Int J Biostat 2011;7:6.

28. Schneider C, Tyler LE, Scull EF, et al. A case-control study investigating factors of preoperative delay in emergency laparotomy. Int J Surg 2015;22:131-5.

29. Pearse RM, Dana EC, Lanigan CJ, et al. Organisational failures in urgent and emergency surgery. A potential peri-operative risk factor. Anaesthesia 2001;56: 684-9.

30. Katsanis N, Rosenberg SM. An age-old problem. PLoS Genet 2007;3:e37.

31. Gale SC, Shafi S, Dombrovskiy VY, et al. The public health burden of emergency general surgery in the United States: a 10-year analysis of the Nationwide Inpatient Sample - 2001 to 2010. J Trauma Acute Care Surg 2014;77:202-8.

32. Health indicators 2007. Ottawa: Canadian Institute for Health Information; 2007.

33. Hip Fracture Accelerated Surgical Treatment and Care Track (HIP ATTACK) Investigators. Accelerated care versus standard care among patients with hip fracture: the HIP ATTACK pilot trial. CMAJ 2014;186:E52-60.

\section{Competing interests: None declared.}

This article has been peer reviewed.

Affiliations: Departments of Anesthesiology (Mclsaac, Abdulla, Yang), Surgery (Sundaresan) and Medicine (Forster), University of Ottawa; The Ottawa Hospital (Mclsaac, Yang, Sundaresan, Doering, Forster), Civic Campus; Ottawa Hospital Research Institute (Mclsaac, Thavorn, Forster), Ottawa, Ont.; Institute for Healthcare Optimization (Green Vaswani), Newton, MA

Contributors: All of the authors contributed to study conception, and Daniel Mclsaac,
Karim Abdulla and Alan Forster contributed to study design. Daniel Mclsaac, Karim Abdulla, Kednapa Thavorn and Alan Forster contributed to the analysis, and all of the authors contributed to interpretation of the data. Daniel Mclsaac wrote the manuscript, with contributions from Karim Abdulla and Alan Forster. All of the authors reviewed the manuscript for important intellectual content, approved the final version for publication and agreed to act as guarantors of the work.

Funding: Daniel Mclsaac receives salary support from The Ottawa Hospital Department of Anesthesiology. No other funding was received.

Acknowledgements: This project was undertaken in collaboration with the Institute for Healthcare Optimization (Boston, MA; ihoptimize.org). The authors thank Jocelyn Tufts for assistance in creating the analytical data set.

Accepted: Feb. 6, 2017

Correspondence to: Daniel Mclsaac, dmcisaac@toh.on.ca 